\title{
Adjunct clinical interventions that influence vaginal birth after cesarean rates: systematic review
}

\author{
Aireen Wingert ${ }^{1}$, Cydney Johnson ${ }^{1}$, Robin Featherstone ${ }^{1,2}$, Meghan Sebastianski ${ }^{2}$, Lisa Hartling ${ }^{1,2}$ \\ and R. Douglas Wilson ${ }^{3^{*}}$ (D)
}

\begin{abstract}
Background: Rates of cesarean deliveries have been increasing, and contributes to the rising number of elective cesarean deliveries in subsequent pregnancies with associated maternal and neonatal risks. Multiple guidelines recommend that women be offered a trial of labor after a cesarean (TOLAC). The objective of the study is to systematically review the literature on adjunct clinical interventions that influence vaginal birth after cesarean (VBAC) rates.

Methods: We searched Ovid Medline, Ovid Embase, Wiley Cochrane Library, CINAHL via EBSCOhost; and Ovid PsycINFO. Additional studies were identified by searching for clinical trial records, conference proceedings and dissertations. Limits were applied for language (English and French) and year of publication (1985 to present). Two reviewers independently screened comparative studies (randomized or non-randomized controlled trials, and observational designs) according to a priori eligibility criteria: women with prior cesarean sections; any adjunct clinical intervention or exposure intended to increase the VBAC rate; any comparator; and, outcomes reporting changes in TOLAC or VBAC rates. One reviewer extracted data and a second reviewer verified for accuracy. Two reviewers independently conducted methodological quality assessments using the Mixed Methods Appraisal Tool (MMAT).
\end{abstract}

Results: Twenty-three studies of overall moderate to good methodological quality examined adjunct clinical interventions affecting TOLAC and/or VBAC rates: system-level interventions (three studies), provider-level interventions (three studies), guidelines or information for providers (seven studies), provider characteristics (four studies), and patient-level interventions (six studies). Provider-level interventions (opinion leader education, laborist, and obstetrician second opinion for cesarean sections) and provider characteristics (midwifery antenatal care, physicians on night float call schedules, and deliveries by family physicians) were associated with increased rates of VBAC. Few studies employing heterogeneous designs, sample sizes, interventions and comparators limited confidence in the effects. Studies of system-level and patient-level interventions, and guidelines/information for providers reported mixed findings.

Conclusions: Limited evidence indicates some provider-level interventions and provider characteristics may increase rates of attempted and successful TOLACs and/or VBACs, whereas other adjunct clinical interventions such as system-level interventions, patient-level interventions, and guidelines/information for healthcare providers show mixed findings.

Keywords: Vaginal birth after cesarean, Trial of labor after cesarean, Systematic review

\footnotetext{
*Correspondence: doug.wilson@ahs.ca

${ }^{3}$ Department of Obstetrics and Gynecology, Cumming School of Medicine,

University of Calgary, 1403 - 29 Street NW, Calgary, AB T2N 2T9, Canada

Full list of author information is available at the end of the article
}

(c) The Author(s). 2018 Open Access This article is distributed under the terms of the Creative Commons Attribution 4.0 International License (http://creativecommons.org/licenses/by/4.0/), which permits unrestricted use, distribution, and reproduction in any medium, provided you give appropriate credit to the original author(s) and the source, provide a link to the Creative Commons license, and indicate if changes were made. The Creative Commons Public Domain Dedication waiver (http://creativecommons.org/publicdomain/zero/1.0/) applies to the data made available in this article, unless otherwise stated. 


\section{Background}

A cesarean delivery is the most common surgery in Canada, with one of the main contributors being an elective cesarean delivery in subsequent pregnancies [1, 2]. Canadian cesarean delivery rates have increased from $18.7 \%$ in 1997 to $27.5 \%$ in 2014 [3] and continue to increase globally, [4] the result of an interplay of multiple factors including, but not limited to, shifting clinical environments, provider and patient preferences, and changing maternal demographics (e.g., obesity, chronic disease prevalence and advanced age) [5-9]. These factors can lead to higher-risk and more complex pregnancies and deliveries and an increased likelihood of a cesarean delivery $[10,11]$.

Depending on the etiology or indication, a cesarean delivery contributes to short- and long-term risks for both mother and infant $[12,13]$. The Society of Obstetricians and Gynaecologists of Canada (SOGC) recommends that a trial of labor be offered to women with one previous transverse low-segment cesarean section [12]. A woman's willingness to undergo a trial of labor after cesarean (TOLAC) may be influenced by a multitude of factors [14]. While a vaginal birth after a cesarean (VBAC) may be desired by some women, the patient-level benefits associated with a VBAC from avoiding major abdominal surgery and risk of complications in future pregnancies must be weighed against the potential for serious harms such as a failed TOLAC and subsequent maternal and neonatal morbidity including an unplanned repeat cesarean delivery [15]. For women with more than one previous cesarean delivery, a VBAC is likely to be successful, but with an estimated higher risk of uterine rupture $(0.2$ to $1.5 \%$ with a transverse uterine incision, 1.0 to $1.6 \%$ with a low-vertical uterine incision) [12]. This SOGC statement is consistent with recommendations from the American College of Obstetrics and Gynecology (ACOG) [16, 17].

This systematic review aimed to evaluate adjunct clinical interventions that could be directed at or used by patients, families, healthcare providers, and hospitals/health systems to influence the uptake and success of VBAC.

\section{Methods}

This summation followed the standardized methods and guidelines for systematic reviews, $[18,19]$ and used an 'a priori' protocol (available from authors).

\section{Literature search}

A research librarian searched the following databases in May 2017: Ovid Medline (1946-), Ovid Embase (1980-), Wiley Cochrane Library (inception-), CINAHL via EBSCOhost (1937-) and Ovid PsycINFO (1806-). Limits were applied for language (English and French) and publication year (1985). The search strategy used the
Conference Proceedings Citation Indexes (Clarivate Analytics) and hand-searched meeting abstracts from the past 2 years from the following associations: The Society for Maternal-Fetal Medicine (SMFM), the Society of Obstetricians and Gynaecologists of Canada (SOGC), and the American Congress of Obstetricians and Gynecologists. Finally, we searched ClinicalTrials.gov and ProQuest Dissertations \& Theses Global (1861-). Reference lists of relevant systematic reviews were reviewed for potentially eligible studies. The detailed search strategy is in Additional file 1: Appendix 1.

\section{Eligibility criteria}

The study population was women who had a previous cesarean delivery including women with more than one prior cesarean delivery. Births attended by any healthcare provider (e.g., family physician, midwife, obstetrician/gynecologist) were eligible. Any intervention or exposure that was intended to effect a change in the VBAC rate among women with a prior cesarean delivery was eligible for inclusion. To be eligible, studies had to report on at least one of the outcomes of interest to the review: the primary outcome was change(s) in VBAC rates; secondary outcomes included TOLAC rates, or where reported, rates of successful VBAC among women undergoing a TOLAC. Studies that examined deliveries in any setting (e.g., hospitals, primary care centers, birthing units, home births) were eligible. All study designs (randomized [RCT] and non-randomized controlled trials [NRCT], and observational studies) with a comparison group were eligible for inclusion.

Studies were not considered eligible if: all women had three or more prior cesareans; multiple births of three or more fetuses were explicitly included; there was an absence of an exposure or intervention, or an inappropriate exposure/intervention was used (e.g., ethnicity, socioeconomic status, insurance status, physician traits, malpractice premiums); there was absence of a comparator, or an inappropriate comparator was used (e.g., no data for comparison groups in before-after study designs, women without a previous cesarean delivery); VBAC rates or change were not reported; or, they were not primary research (e.g., letter, editorial, commentary). Systematic reviews were not included; reference lists therein were screened for potentially relevant studies.

\section{Study selection}

Two reviewers (CJ and AW) independently screened titles and abstracts using a priori eligibility criteria. Full texts of potentially relevant publications were retrieved and independently reviewed in duplicate for inclusion; disagreements were resolved through discussion or third-reviewer consultation. 


\section{Data extraction}

One reviewer extracted data and another verified data from each included study using a pre-specified and piloted form. Data were extracted for relevant study characteristics (design features), population (number of previous cesarean deliveries, parity), intervention, comparator, outcome (TOLAC rate [the number of women with a previous cesarean delivery who attempt a vaginal delivery] and VBAC rate [the number of women with a previous cesarean delivery who undergo a successful vaginal delivery]), funding source, and setting.

Intention-to-treat results were extracted from individual studies whenever possible. For dichotomous data on rates of TOLAC and VBAC, we reported counts or proportions, and sample size, by study arm. Results of statistical tests (e.g., $p$-values) or summary statistics (e.g., odds ratio $[\mathrm{OR}]$, risk ratio $[\mathrm{RR}]$, with confidence intervals $[\mathrm{CI}]$ ) were extracted whenever these were reported within the studies.

\section{Assessment of methodological quality}

Two reviewers independently assessed the methodological quality of included studies; disagreements were resolved via consensus. All studies were assessed using the Mixed Methods Appraisal Tool (MMAT [20]), a tool designed for systematic reviews that include multiple study designs.

\section{Data synthesis}

Due to heterogeneity of interventions and comparators, pooling of data across studies for a meta-analysis was not appropriate; therefore, results were described narratively.

\section{Assessment of overall quality of evidence}

Data from studies were not pooled for summary effect estimates; therefore, assessment of the quality of the body of evidence using the Grading of Recommendations Assessment, Development and Evaluation (GRADE [21]) was not conducted.

\section{Results}

The literature search identified 5269 unique records eligible for inclusion. After screening titles and abstracts, 305 potentially relevant articles were identified. Full text screening yielded 23 studies [22-44] included in the review. The screening process is illustrated in Fig. 1.

Studies published from 1987 to 2017 were conducted in the United States (13 studies; 57\% [23-27, 30, 34, 35, $37-39,42,44]$ ), Canada (three studies; $13 \%[28,32,36]$ ), United Kingdom (three studies; 13\% [33, 40, 41]), Australia (one study; 4\% [29]), China (one study [43]), Portugal (one study; 4\% [22]), and Taiwan (one study; $4 \%$ [31]). Funding was from non-industry sources (ten studies; 43\% [25-28, 30, 32, 33, 36, 40, 42]), without funding (two studies; 9\% [22, 43]), or was not reported (11 studies; 48\% [23, 24, 29, 31, 34, 35, 37-39, 41, 44]). The sample size varied depending on unit of reporting, with a mean of 1276 women (14 studies; [23, 25-30, 32, $33,36,40-43]$ range 96 to 4732) or 306,097 deliveries (nine studies; [22, 24, 31, 34, 35, 37-39, 44] range 5308 to $1,260,186)$.

The majority of studies included women (or records of women) who delivered in hospital (20 studies; [23-25, 27-34, 36-44] 87\%), health clinics (one study; [26] 4\%), and in multiple settings including hospitals and at home (two studies; [22, 35] 9\%). Of the 12 studies [23, 25, 26, $28,29,32,36,39,40,42-44](52 \%)$ that reported maternal age, a wide range of women (18 years and younger to 40 years and older) were represented. Studies explicitly reported including women with 1 prior cesarean delivery (six studies [26, 28, 29, 40-42]), one or two prior cesarean deliveries (one study [37]), and at least one prior cesarean delivery (three studies [23, 33, 36]); the latter three included some women with three or more prior cesarean deliveries.

While all studies reported the proportion of women who had a VBAC, about half (13 studies; [25, 27-30, 32, $34,36,37,40-42,44] 57 \%)$ provided comparative proportions of women who had a TOLAC.

Most studies were cohorts (16 studies; one non-concurrent cohort contained 3-arms [22, 23, 25, 29-31, 34$42,44]$ ); a small proportion were RCTs (five studies; three trials contained three-arms [26, 28, 32, 33, 43]), before-after (one study [24]), and cross-sectional (one study [27]).

Table 1 summarizes the strategies/outcome themes among the studies. Tables 2, 3, 4, 5 and 6 summarize the included studies by categories of interventions. Additional file 1: Appendix 2 details characteristics of the individual studies.

\section{Methodological quality of included studies}

All of the studies received a score for having a clear research question or objective, and for collecting data that addressed the intended research question.

Of the five RCTs, four (80\%) [26, 28, 32, 33] described the randomization process clearly, but only one (20\%) [33] clearly described allocation concealment or blinding. Four (80\%) RCTs [28, 32, 33, 43] had complete outcome data for at least $80 \%$ of the participants. Three $(60 \%)$ RCTs $[26,28,33]$ had a withdrawal or drop-out rate of less than $20 \%$. Overall, one (25\%) RCT [33] met all of the criteria (four out of four stars).

The majority (16 studies; $89 \%$ ) [22-24, 27, 29-31, $35-42,44]$ of the non-randomized controlled studies recruited participants or organizations in a way that minimized selection bias. Most (17 studies; 94\%) [22- 


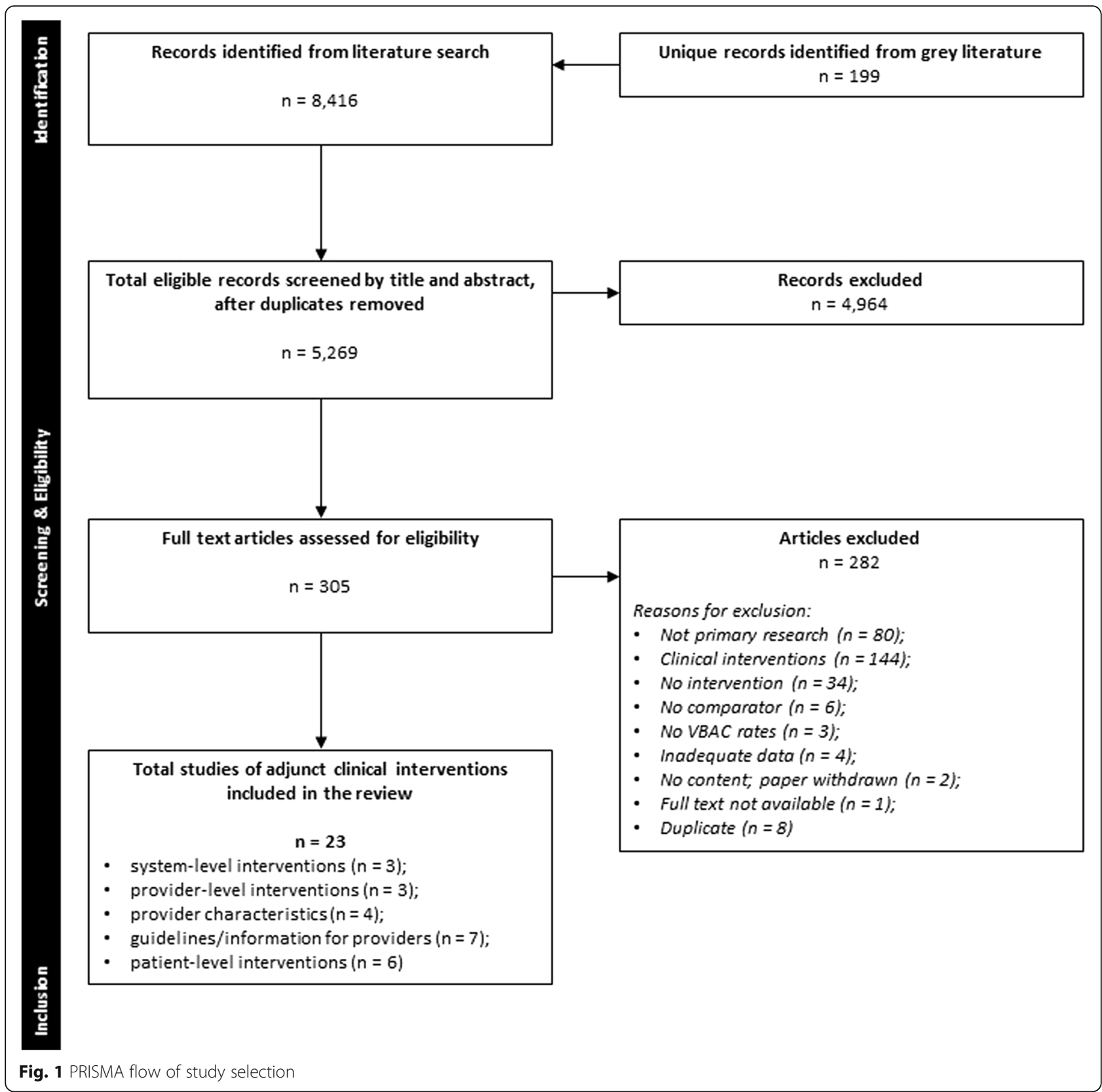

$25,27,30,31,34-42,44]$ studies used appropriate measurements for the interventions/exposures and outcomes, and used interventions that did not present potential contamination between groups. Only seven (39\%) studies [23, 24, 27, 39, 40, 42, 44] accounted for important differences between groups, or controlled for such differences in the data analysis. Many studies $(n=$ 16 ; 89\%) [22-25, 27, 29, 31, 34-40, 42, 44] had complete outcome data for at least $80 \%$ of the participants, or an acceptable response or follow-up rate (i.e., $60 \%$ or above). Overall, seven (39\%) [23, 24, 27, 39, 40, $42,44]$ studies scored four stars (out of four).
Methodological quality assessments are summarized in Table 7; detailed study assessments are in Additional file 1: Appendix 3.

\section{TOLAC and VBAC rates}

\section{System-level interventions}

Three studies [22, 24, 31] examined system-level interventions (Table 2). One non-concurrent cohort compared deliveries in continental Portugal before and after a concerted action to reduce cesarean section rates based on transmission and training of healthcare professionals as well as targeted cesarean delivery rates for 
Table 1 Summary of adjunct clinical interventions of included studies

\begin{tabular}{|c|c|c|c|c|}
\hline Intervention Category & Strategy/Outcome Themes & TOLAC $^{a}$ & $\mathrm{VBAC}^{\mathrm{a}}$ & Study (study design) \\
\hline \multirow[t]{5}{*}{ System-level } & Education and training of providers & NA & + & Ayres-de-Campos 2015 (NCC) \\
\hline & Targeted CD rates with hospital funding & NA & + & Ayres-de-Campos 2015 (NCC) \\
\hline & Targeted VBAC rates with hospital funding & NA & + & Liu 2013 (NCC) \\
\hline & Hospital peer-review of CDNBAC & NA & NS; & Bickell 1996 (BA); \\
\hline & & &,$+ N C$ & Liu 2013 (NCC) \\
\hline \multirow[t]{3}{*}{ Provider-level } & Opinion leader VBAC & + & + & Lomas 1991 (RCT) \\
\hline & Hospital with laborists & + & $+\mathrm{NS}$ & Feldman 2015 (CS) \\
\hline & Second opinion requirement for all CDs & + & + & Myers 1993 (NCC) \\
\hline \multirow[t]{4}{*}{ Provider characteristics } & Midwifery vs. non-midwifery provider & + & + & Zhang 2016 (RCT); \\
\hline & & & & White 2016 (NCC) \\
\hline & Family physician vs. obstetrician & + & + & Russillo 2008 (CS) \\
\hline & Night float call vs. traditional call & + & + & Yee 2017 (RC) \\
\hline \multirow[t]{7}{*}{ Provider guidelines/information } & Education and management direction & + & + & Bellows 2016 (NCC); \\
\hline & & & & Kosecoff 1987 (RC); \\
\hline & & & & Sanchez-Ramos 1990 (NCC); \\
\hline & & & & Santerre 1996 (NCC); \\
\hline & & - & - & Pinette 2004 (NCC); \\
\hline & & & & Zweifler 2006 (NCC); \\
\hline & & NA & NC & Studnicki 1997 (NCC) \\
\hline \multirow[t]{6}{*}{ Patient-level } & Obstetric information vs. no information & + & + & Wong 2014 (PC) \\
\hline & Verbal vs. written patient information & $+\mathrm{NS}$ & $+\mathrm{NS}$ & Fraser 1997 (RCT); \\
\hline & Dedicated VBAC clinic vs. standard care & NA & + & Gardner 2014 (NCC) \\
\hline & Decision analysis (computerized) vs. brochures & NA & $+\mathrm{NS}$ & Eden 2014 (RCT) \\
\hline & Decision analysis vs. information vs. usual care & NA & $+\mathrm{NS}$ & Montgomery 2007 (RCT) \\
\hline & One-on-one antenatal VBAC counseling vs. standard care & + & - & Cleary-Goldman 2005 (PC) \\
\hline
\end{tabular}

TOLAC trial of labor after cesarean, VBAC vaginal birth after cesarean, NCC non-concurrent cohort, $C D(s)$ cesarean delivery, $B A$ before-after, $R C T$ randomized clinical trial, $C S$ cross-sectional, vs. versus, $R C$ retrospective cohort, $P C$ prospective cohort

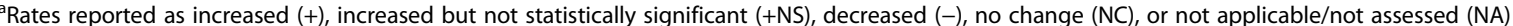

contingency-based hospital funding, and found an increase in the VBAC rate from $16.4 \%(13,399$ of 81,750 VBACs) in 2009 to $32.8 \%(16,859$ of 51,478 VBACs) in $2014(p<0.001)[22]$. Another non-concurrent cohort of deliveries at a tertiary hospital in Taiwan found that rates of vaginal deliveries in women with previous cesarean deliveries increased (from 4.8\% [38 of 800 deliveries] to $12.2 \%$ [231 of 1887 deliveries]) after implementation of direct government funding of hospitals from 2002 to 2005 (rate ratio $0.82,95 \%$ CI $0.74-0.90, p=0.0001$ ), but the rate did not improve further (from 12.2\% [231 of 1887 deliveries] to $11.4 \%$ [ 298 of 2621 deliveries]) with the additional employment of a hospital-based post-operative peer review and audit strategy from 2005 to 2010 (rate ratio $0.98,95 \%$ CI $0.96-0.99, p=0.0003$ ) [31]. One study compared peer reviewed with non-reviewed hospitals (45 [mean 1430 deliveries in 1988 and mean 1503 deliveries in 1993] versus 120 hospitals [mean 1720 deliveries in 1988 and 1993]), and found that VBAC rates increased between the years by 14.6 and $12.7 \%$ (reviewed and non-reviewed hospitals, respectively), although the difference between reviewed and non-reviewed hospitals was not statistically significant [24].

\section{Provider-level interventions}

Three studies examined provider-level interventions $[27,32,34]$ (Table 3). One RCT of community hospitals compared opinion leader education (739 women from four hospitals) and audit and feedback (524 women from four hospitals) to mailed guideline recommendations (1233 women from eight hospitals), and found that women were more likely to attempt a TOLAC when delivering in obstetric departments with influential opinion leaders (38.2\%) compared to units with audit and feedback $(21.4 \%)$ or mailed practice guidelines $(28.3 \%)$ (46\% higher in the opinion leaders group versus the other groups, $p=0.007$ ) [32]. Women were also more likely to have VBACs in the 
Table 2 Summary of studies - system-level interventions

\begin{tabular}{|c|c|c|c|c|c|c|c|}
\hline $\begin{array}{l}\text { Study; } \\
\text { Design; } \\
\text { Country, setting; } \\
\text { Funding }\end{array}$ & $\begin{array}{l}\text { Population; } \\
\text { Study period }\end{array}$ & \multicolumn{3}{|c|}{ Intervention \& comparator (no. of participants) } & $\begin{array}{l}\text { TOLAC } \\
\text { rate }^{a}\end{array}$ & VBAC rate ${ }^{a}$ & $\begin{array}{l}\text { VBAC/ } \\
\text { TOLAC } \\
\text { rate }^{a}\end{array}$ \\
\hline $\begin{array}{l}\text { Ayres- } \\
\text { De-Campos (2015) } \\
\text { Non-concurrent } \\
\text { cohort } \\
\text { Portugal, } \\
\text { state-owned } \\
\text { hospitals, private } \\
\text { hospitals } \\
\text { \& home births } \\
\text { No funding }\end{array}$ & $\begin{array}{l}\text { All deliveries from } \\
\text { state-owned hospitals, } \\
\text { private hospitals \& } \\
\text { home births during } \\
\text { study period } \\
\text { January 1, 2000- } \\
\text { September 30, } 2014\end{array}$ & $\begin{array}{l}\text { Grp } 1(2000-2009): \\
\text { no concerted action } \\
(n=913,219)\end{array}$ & \multicolumn{2}{|c|}{$\begin{array}{l}\text { Grp } 2 \text { (2010-2014): concerted } \\
\text { action by independent } \\
\text { committee (visits to state- } \\
\text { owned hospitals with CS rates } \\
\text { > 35\%; meetings with } \\
\text { obstetric \& midwifery staff; } \\
\text { training courses) ( } n=346,157)\end{array}$} & NR & $\begin{array}{l}\text { 2000: } 14,993(14.5 \%) ; \\
\text { 2001: 13,298 (13.7\%); } \\
\text { 2002: 15,360 (15.8\%); } \\
\text { 2003: 13,890 (14.8\%); } \\
\text { 2004: 13,710 (15.0\%); } \\
\text { 2005: 13,147 (14.6\%); } \\
\text { 2006: 15,700 (17.9\%); } \\
\text { 2007: 15,431 (18.1\%); } \\
\text { 2008: 13,837 (16.2\%); } \\
\text { 2009: 13,399 (16.4\%) } \\
\text { vs. } \\
\text { 2010: } 14,834(17.9 \%) ; \\
\text { 2011: 17,624 (22.8\%); } \\
\text { 2012: 18,076 (25.1\%); } \\
\text { 2013: 16,365 (25.8\%); } \\
\text { Jan-Sept } 2014: 16,859 \\
\text { (32.8\%) }\end{array}$ & NR \\
\hline $\begin{array}{l}\text { Bickell (1996) } \\
\text { Controlled } \\
\text { before-after } \\
\text { US, hospitals with } \\
\text { high/average/low } \\
\text { cesarean rate } \\
\text { Funding NR }\end{array}$ & $\begin{array}{l}\text { Hospitals from eight } \\
\text { designated Health } \\
\text { Service Areas of New } \\
\text { York State } \\
1988 \text { \& } 1993\end{array}$ & $\begin{array}{l}\text { I: reviewed hospitals, } \\
\text { external peer reviews } \\
\text { by ACOG trained } \\
\text { team (audit \& feedback) } \\
\text { ( } 45 \text { hospitals; mean } \\
\text { 1400-1500 deliveries) }\end{array}$ & \multicolumn{2}{|c|}{$\begin{array}{l}\text { C: non-reviewed hospitals, } \\
\text { had an obstetric service } \\
\text { (120 hospitals; mean } 1700 \\
\text { deliveries) }\end{array}$} & NR & $\begin{array}{l}\text { 1988: } \\
\text { I: mean } 10.1 \pm 1.4 \% \\
\text { C: mean } 12.1 \pm 0.9 \% \\
\text { NS }(p>0.01) \\
\text { 1993: } \\
\text { I: mean } 24.8 \pm 2.0 \% \\
\text { C: mean } 24.8 \pm 1.1 \% \\
\text { NS }(p>0.01)\end{array}$ & NR \\
\hline $\begin{array}{l}\text { Liu (2013) } \\
\text { Non-concurrent } \\
\text { cohort } \\
\text { Taiwan, tertiary } \\
\text { hospital } \\
\text { Funding NR }\end{array}$ & $\begin{array}{l}\text { All pregnant women } \\
\text { delivering by } \\
\text { cesarean section } \\
\text { June 2001-August } \\
2010\end{array}$ & $\begin{array}{l}\text { Period } 1 \text { (June 2001- } \\
\text { July 2002): before } \\
\text { implementation of } \\
\text { budget systems } \\
(n=800)\end{array}$ & $\begin{array}{l}\text { Period } 2 \text { (July } \\
\text { 2002-August } \\
\text { 2005): global } \\
\text { budget system } \\
(n=1887)\end{array}$ & $\begin{array}{l}\text { Period } 3 \text { (August } \\
\text { 2005-2010): } \\
\text { hospital-based } \\
\text { self-management } \\
\text { program } \\
(n=2621)\end{array}$ & NR & $\begin{array}{l}\text { P1: } 38(4.8 \%) \\
\text { P2: } 231(12.2 \%) \\
\text { P3: } 298(11.4 \%) \\
\text { Period 1 vs. } 2 \\
p<0.001 \\
\text { Period } 2 \text { vs. } 3, p=0.3950\end{array}$ & NR \\
\hline
\end{tabular}

no. number, TOLAC trial of labor after cesarean, VBAC vaginal birth after cesarean, Grp group, $n$ number, CS cesarean section, NR not reported, vs. versus, US United States, I intervention, ACOG American College of Obstetricians and Gynecologists, C comparator, NS not significant

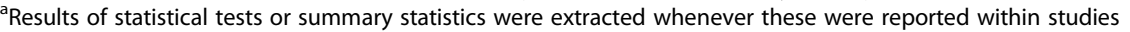

opinion leader group (25.3\%) compared with the audit and feedback (11.8\%) and guideline groups $(14.5 \%)$ (85\% higher in the opinion leaders group versus the other groups, $p=0.003$ ) [32]. A cross-sectional study found that a higher proportion of women with prior cesarean delivery had a TOLAC in hospitals employing laborists (356 of 2621 women; 13.6\%) compared with hospitals without laborists (201 of 2111 women; 9.5\%) [27]. A higher rate of successful VBACs occurred in the same group, however the result was not statistically significant $(9.7 \%$ versus $6.5 \%$; adjusted odds ratio (aOR) 1.10, 95\% CI 0.82-1.47, $p=0.5417$ ) [27]. A non-concurrent cohort comparing deliveries in 1985 with deliveries in 1986 to 1991 after the implementation of a hospital initiative utilizing a second opinion by an obstetrician for primary and repeat cesarean deliveries, found increased rates of TOLAC (45.0\% versus range 68.4 to $91.3 \%$, pre- versus post-intervention, respectively) and VBAC $(23.8 \%$ versus range 54.9 to $67.4 \%$, pre- versus post-intervention, respectively) [34].

\section{Provider characteristics}

Four studies [36, 40, 42, 43] examined the effect of provider characteristics on VBAC rates (Table 4). A small RCT of women in labor compared midwifery care $(n=$ $48)$ with standard maternity care $(n=48)$; the authors reported a higher proportion of VBAC among women receiving continuous midwifery care from the antenatal to postnatal period $(87.5 \%$ versus $66.7 \%$ of women, $p<$ 0.05 ) [43]. Another study examined midwifery care and found that among women with one previous cesarean delivery, there was a higher rate of attempted VBACs in the post-intervention (midwifery-led antenatal care; 153 of 196 women; 78.1\%) compared with the pre-intervention group (traditional obstetrician-led antenatal care; 143 of 209 women; 68.4\%) [40]. More VBACs occurred in the group who received care from a midwife in 2011 (120 of 196 women; $61.2 \%$ ) than among women who received obstetrician-led antenatal care in 2008 (98 of 209 women; 46.9\%, aOR 1.79; 95\% CI 1.17-2.75, $p<0.05)$. One retrospective cohort compared physicians with a traditional call schedule (946 women) with physicians on 
a night float call schedule (556 women); eligible women were more likely to undergo a TOLAC when delivered by physicians on a night float call system (OR 2.50, 95\% CI 1.96-3.20, $p<0.001)$ and the effect persisted when the groups were adjusted for body-mass index (BMI), gestational age (GA) and physician (aOR 2.64, 95\% CI $1.65-4.25, p<0.001$ ) [42]. A cross-sectional study of women with at least one previous cesarean delivery with a singleton delivery compared women delivered by an obstetrician $(n=3493)$ with women delivered by a family physician $(n=201)$, and found that more TOLACs occurred in the latter than the former group $(81.1 \%$ versus $50.6 \%, p<0.001)$ as well as VBACs (61.7\% versus $32.5 \%)$ [36].

\section{Guidelines or information for providers}

Seven non-concurrent cohort studies in the US [23, 30, $35,37-39,44]$ examined VBAC rates before and after guidelines or information for providers were implemented (Table 5). Kosecoff et al. compared VBAC rates in 1979 and 1980 (35 and 64 women, respectively) before the National Institutes of Health conference recommendations, with rates in 1981 to 1982 (70 women); a greater proportion of women had a TOLAC (5.7 and $11.0 \%$ pre- versus $28.6 \%$ post-recommendations) and a VBAC (5.7 and 6.3\% pre- versus $15.7 \%$ post-recommendations) after the conference recommendations (adjusted positive linear trend of 2.4 [5.8\%] for TOLAC and 2.1 [4.5\%] for VBAC) [30]. Another study comparing before (1987-1988) and after (1988-1991) the ACOG practice guidelines were implemented reported that VBAC rates increased by 5.6 percentage points as a result of the guideline and its information dissemination [38]. Pinette et al. also compared rates of VBAC before (1998) and after (1999-2001) ACOG guidelines were revised to require the presence of surgical personnel throughout a trial of labour, and found a marked decline in hospital VBAC data (relative risk 3.5, 95\% CI 3.1-4.2, $p<0.01$ ), citing factors such as patient refusal post-counselling, inability of institutions to meet requirements, and lack of support from the obstetric service [35]. Zweifler et al. examined the effect of the ACOG revision to provide immediate cesarean capability (1996 to 1999 versus 2000 to 2002, before versus after, respectively) and found that there were comparatively fewer TOLACs $(24.0 \%$ before versus $13.5 \%$ after guideline revision, $p<0.001)$ and successful VBACs among women with TOLACs $(82.8 \%$ [41,961 of 50,670 deliveries] before versus $81.8 \%$ [19,273 of 23,573 deliveries] after guideline revision) [44]. In a study focused on the impact of state-legislated practice guidelines, the authors reported that dissemination alone did not significantly increase the VBAC rate (7151 of 23,142 deliveries; $30.9 \%$ post-guideline in 1993) compared with the years leading up to the change (4816 of
22,091 deliveries [21.8\%] in 1990; 5540 of 21,461 deliveries [25.6\%] in 1991; and, 6133 of 22,970 deliveries [26.7\%] in 1992) [39]. A study compared intrapartum management of women with prior cesareans before (1986-1987) and after (1988-1989) hospital guideline changes incorporated centralized decision-making, and found that rates of TOLAC increased from 31.7\% (139 out of 438 women in 1986) to $84.0 \%$ (487 out of 580 women in 1989; $p<0.0001$ ), and that the proportion of these women with subsequent VBACs also increased (from $64.7 \%$ [90 out of 139 women in 1986] to $82.8 \%$ [403 out of 487 women in 1989, $p<0.0001$ ) [37]. Bellows et al. examined changes to hospital policies for TOLAC eligibility and labor induction guidelines; the authors reported that while the "overall VBAC rate" (number of women with a prior cesarean who had a VBAC) increased (26.0\% pre- versus $33.0 \%$ post-guidelines, $p<$ 0.0001 ), the "VBAC rate" (number of women who underwent a TOLAC and had a successful VBAC) was unchanged $(78.9 \%$ pre- versus $78.1 \%$ post-guidelines, $p=$ 0.75) [23].

\section{Patient-level interventions}

Six studies $[25,26,28,29,33,41]$ examined patient-level interventions (Table 6). One RCT of women with a single previous low transverse cesarean delivery compared a verbal prenatal education program (641 women) with a written prenatal education program (634 women) and found no evidence of a clinically significant difference for TOLAC rate $(72.5 \%$ versus $69.4 \%$; relative risk 1.1 , $95 \%$ CI $1.0-1.1)$ or VBAC rate $(52.9 \%$ versus $48.9 \%$; relative risk 1.1, 95\% CI 1.0-1.2) [28]. Another RCT compared two interventions (decision analysis aid [235 women] and information program [241 women]) with usual care (239 women), reporting the highest rate of VBAC in the decision analysis group (37.4\% versus $29.2 \%$ versus $30.3 \%$, decision analysis versus information program versus usual care, respectively; no significant differences between groups) and concluded that women who received any decision aid had greater knowledge and less anxiety than women receiving standard obstetric care [33]. Another trial compared an evidence-based computerized decision aid (66 women) with evidence-based educational ACOG brochures (65 women) and reported that women experienced less decisional conflict in the former group compared with the latter, however, there was no significant difference in VBACs $(41.0 \%$ versus $37.0 \%, p=0.724$ ) [26]. A cohort study of patient satisfaction with mode of delivery found that women who received formal one-on-one antenatal counseling $(n=$ 95) had comparatively higher rates of TOLAC (46.3\% versus $38.5 \%$ ) but lower rates of VBAC (27.4\% versus $31.7 \%)$ than women who didn't participate in VBAC counseling $(n=221)$ [25]. A non-concurrent cohort of 


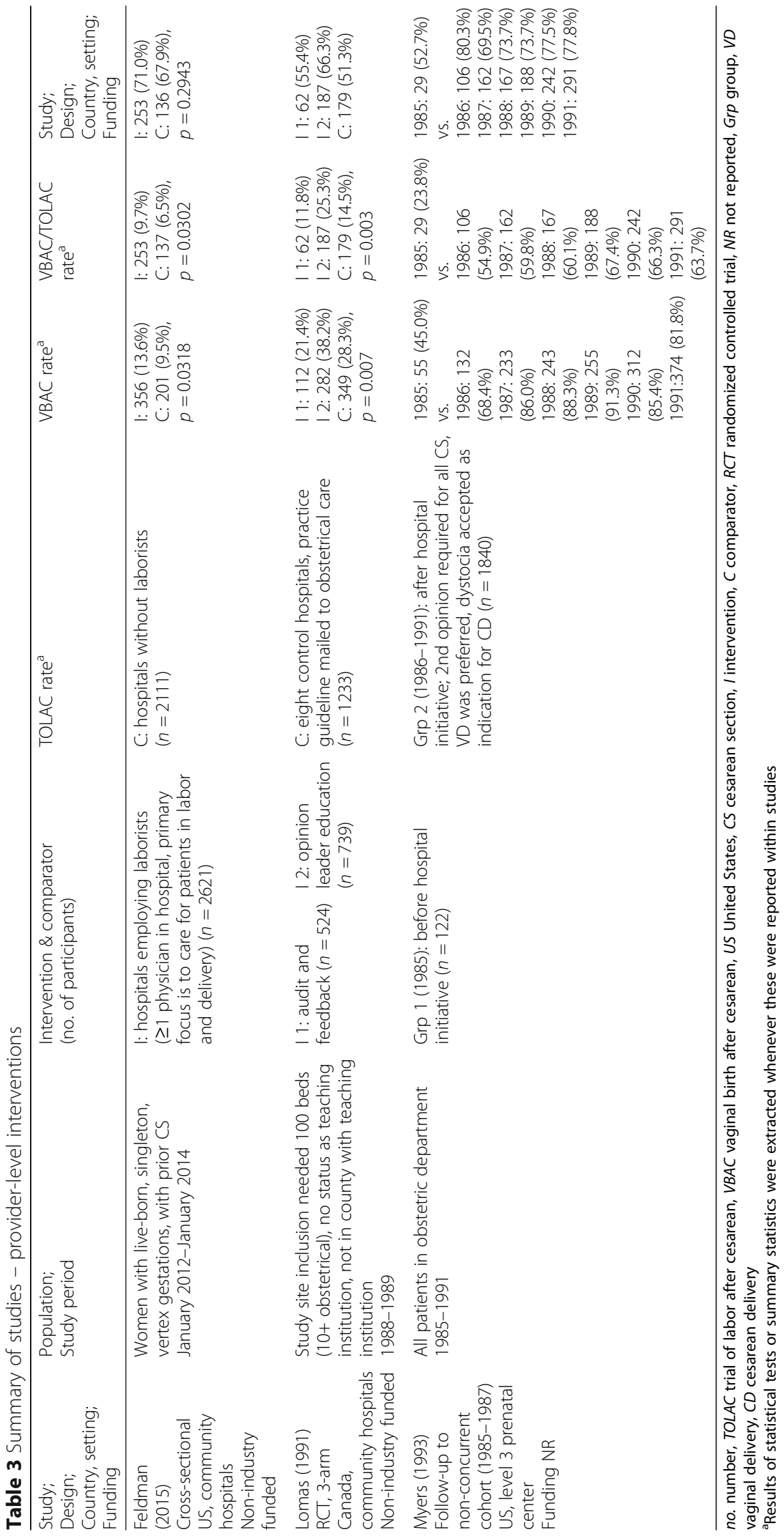




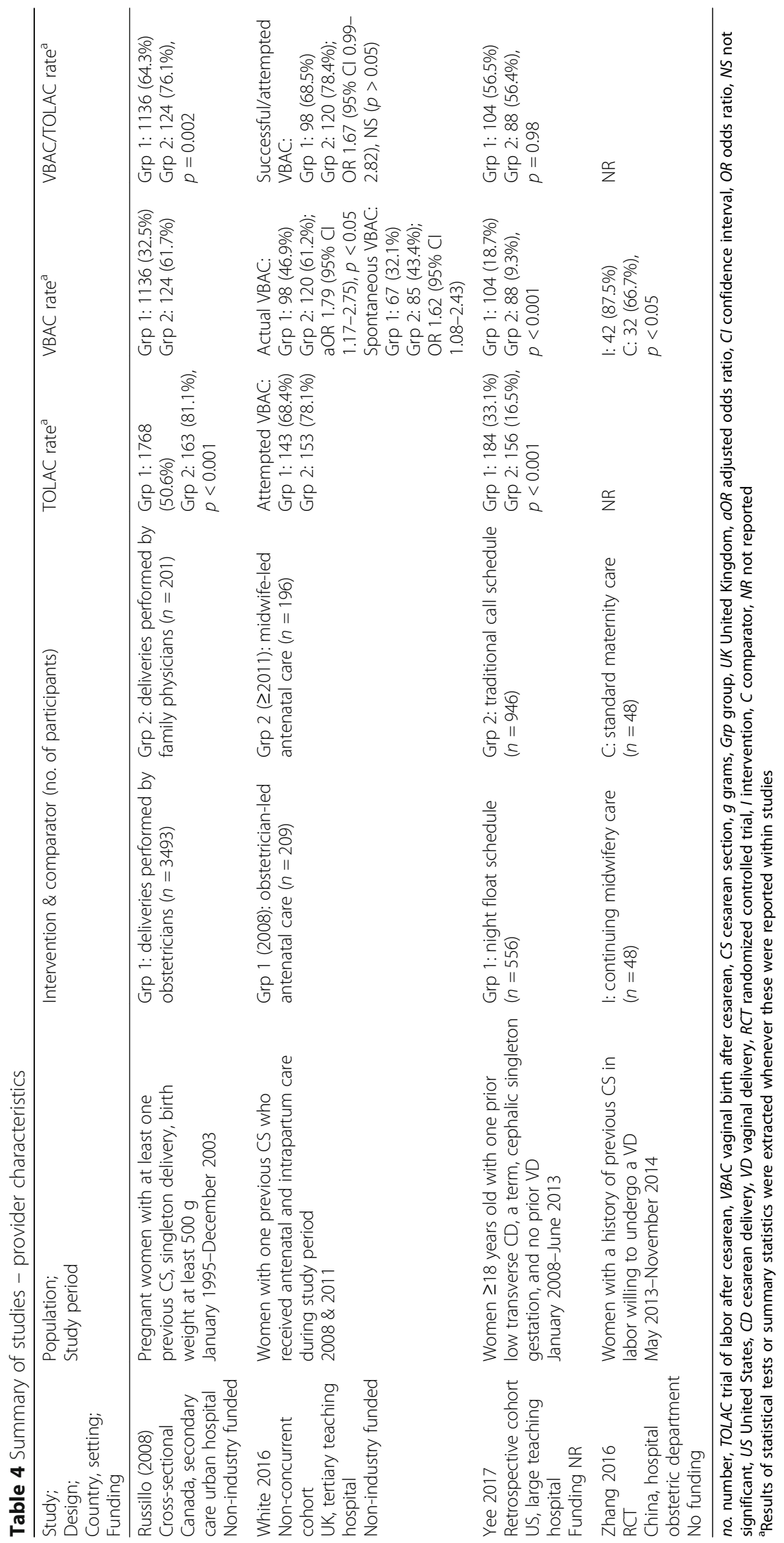




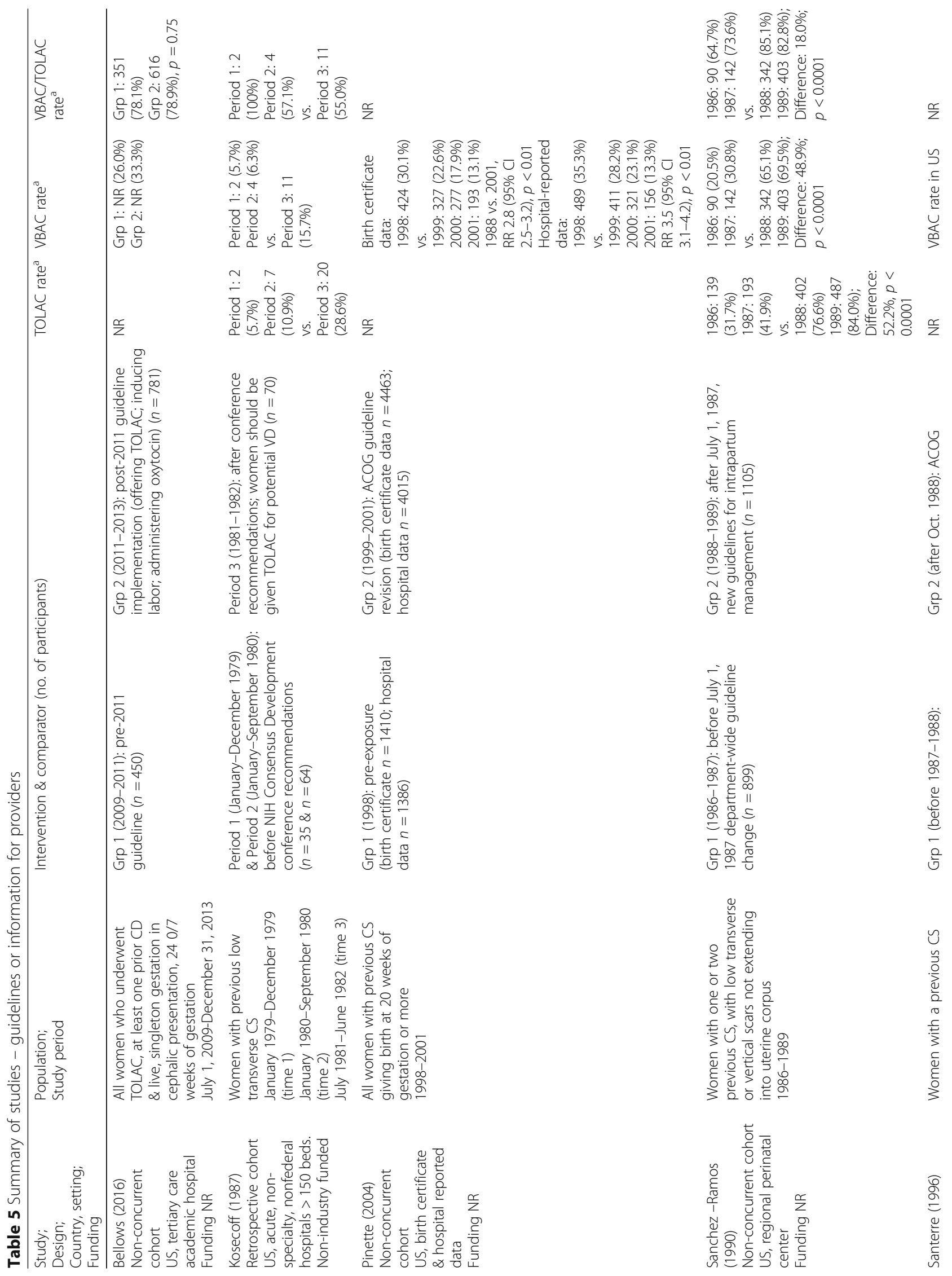


Wingers et al. BMC Pregnancy and Childbirth

(2018) 18:452

Page 11 of 16

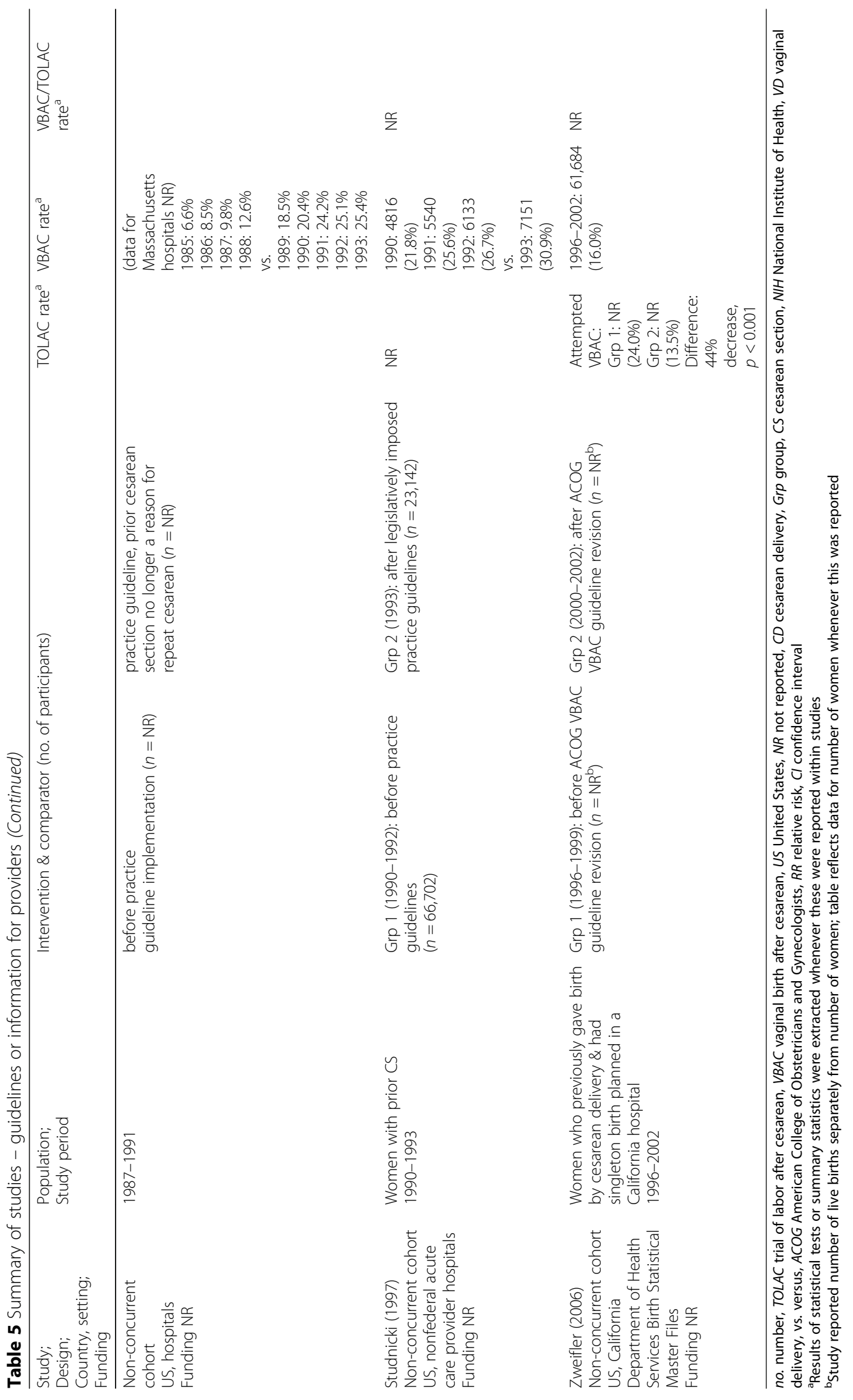




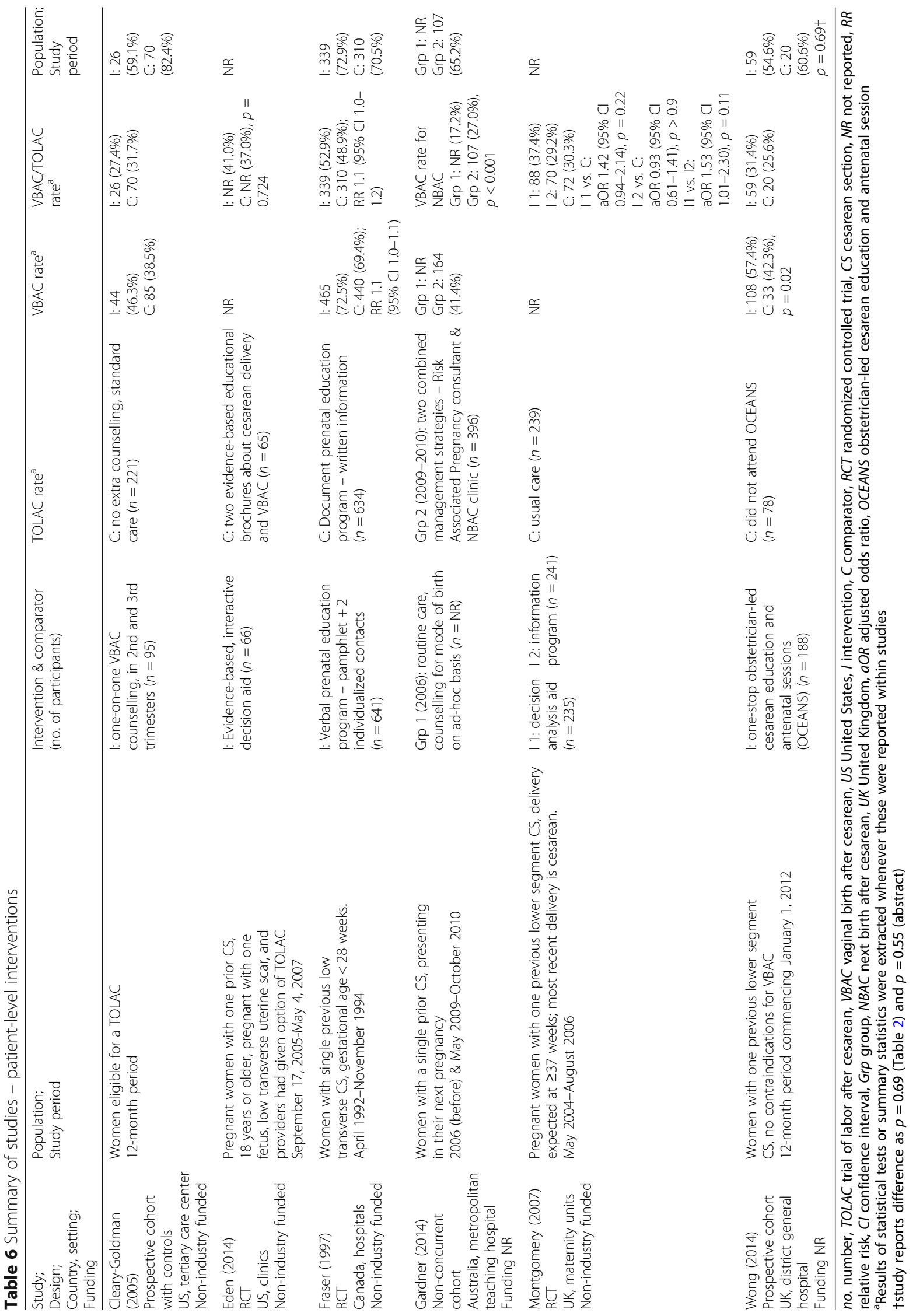




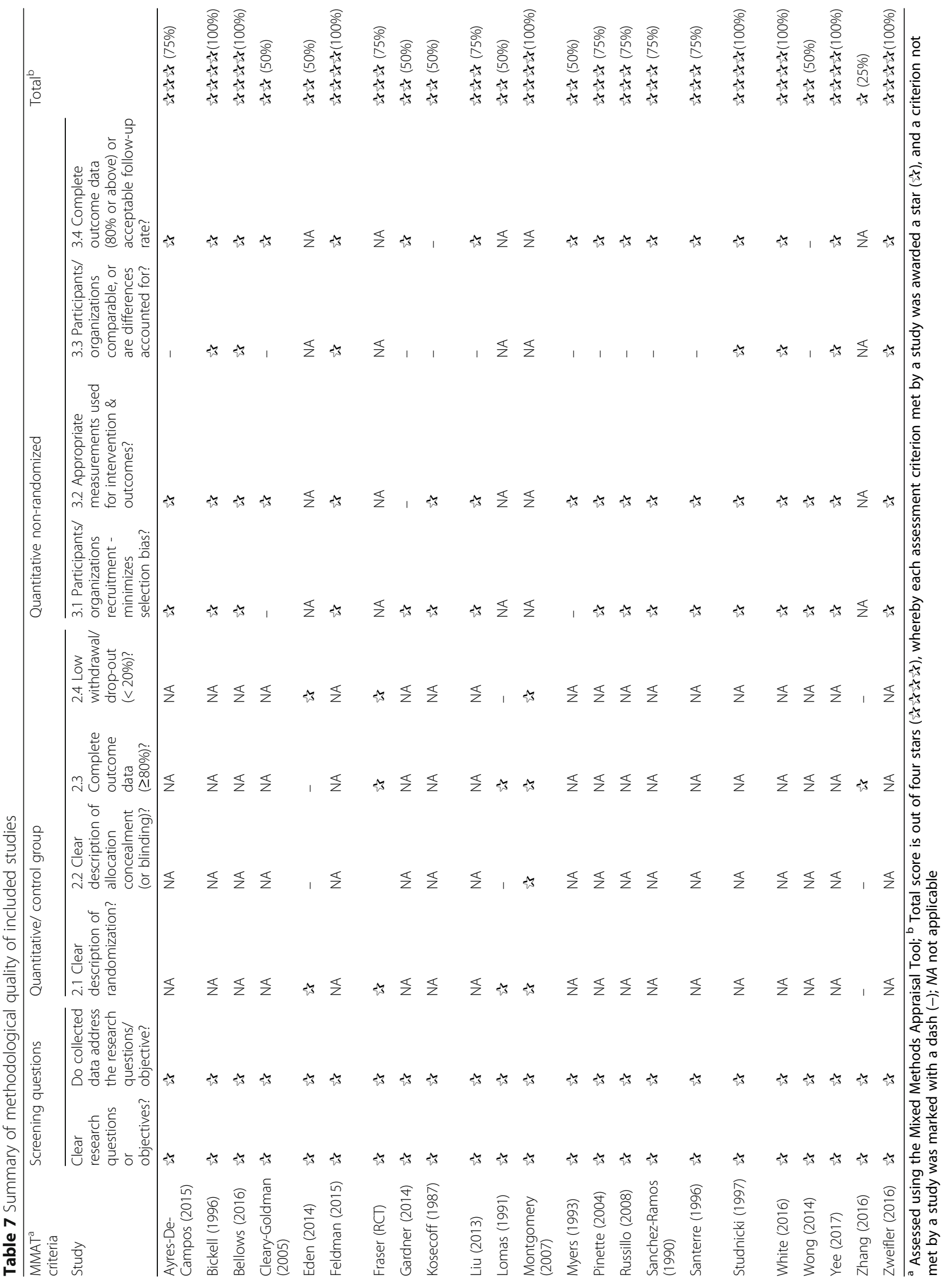


women with a single prior cesarean delivery presenting in their next pregnancy had a higher VBAC rate after the implementation of standardized consultant labor management with a dedicated antenatal clinic (27.0\% versus $17.2 \%, p<0.001)$ compared with women who received routine antenatal care with mode of birth counseling on an ad-hoc basis [29]. Another cohort study reported higher rates of TOLAC (57.4\% versus $42.0 \%, p$ $=0.02)$ and VBAC (31.4\% versus $25.6 \%$ ) among women who attended an obstetrician-led cesarean delivery education and antenatal session $(n=188)$ compared with women who chose not to attend the session $(n=78)$, although the authors concluded that the overall rate of successful vaginal deliveries among women who attempted VBAC was not influenced by the education session [41].

\section{Discussion}

This systematic review of adjunct clinical interventions aimed at influencing the rate of VBACs identified 23 studies which suggest that some provider-level interventions (e.g. opinion leader education in hospitals, employing laborists as providers, and utilizing obstetrician 'second opinion' for all cesarean deliveries), and provider characteristics (i.e., midwifery-led antenatal care, physicians working a night call float schedule, and birth deliveries by a family physician) are associated with higher TOLAC and VBAC rates, while system-level interventions (i.e., education and training of healthcare providers, contingency-based funding for delivery rates, and peer review/audit), patient-level interventions (i.e., different modes of information delivery, and antenatal counseling for women) and provider guidelines/information report mixed findings. The significant study heterogeneity in research designs, interventions and outcomes did not allow for a meta-analysis to be completed.

Other systematic reviews of adjunct clinical interventions to increase VBAC rates have reported similar findings, although eligibility criteria among these reviews differed slightly from the present study. Catling-Paull et al. [45] examined non-clinical interventions (27 studies) and concluded that local guidelines, opinion leaders and individualized information for women can impact the uptake and/or success of VBAC. While the present study also found that opinion leaders increased VBACs, evidence from guidelines had conflicting findings and information for women did not show significant differences between groups. Lundgren et al. [46] evaluated clinician-centered interventions designed to increase VBAC rates (three studies) and concluded that educational strategies delivered by opinion leaders significantly increased VBAC rates, while external peer review and audit and feedback had no significant effect; the present review also found the impact of opinion leader education on VBACs. A systematic review of women-centered interventions to increase VBACs (three studies) concluded that while decision aids and information programs during pregnancy did not appear to affect the rate of VBAC, they reduced women's decisional conflict and increased their knowledge regarding birth options [47]. The present study echoed the findings that information for women was associated with increased VBAC in one study but without significant difference in two studies.

\section{Strengths and limitations of study}

A methodologically rigorous systematic review of the literature was undertaken to capture a broad range of studies of adjunct clinical interventions directed at increasing maternal VBAC rates. However, several factors limit our confidence in effects of interventions, such as inclusion of non-randomized study designs, small number of studies per intervention category, and inconsistent results across heterogeneous studies. Moreover, many studies did not report important maternal baseline characteristics in a consistent manner, including antenatal history (e.g., parity, number of previous cesarean deliveries and vaginal births, medical history/risk factors) or indications (e.g., age, gestational age, fetal risk factors).

\section{Implications for practice}

Based on the available evidence, attempts to increase vaginal births among women with prior cesareans need to incorporate different types of provider or provider-level interventions to achieve a greater likelihood of success. Hospitals that utilize the influential opinion leader model' to educate colleagues and patients can effect a behavior/clinical change by offering more women the opportunity of a VBAC. Staffing community hospitals with laborists may encourage more support for women to attempt a vaginal delivery. Requiring an expert second opinion prior to a cesarean may decrease the proportion of women who undergo cesarean deliveries (exclusive of those performed for acute emergencies) through counseling, thereby increasing choice and the number of attempted VBACs. Low risk maternity providers (e.g., midwives, family physicians) or the continuity of midwifery care may provide women with support and confidence to undergo a VBAC through a personalized and responsive approach. Overall, these are aligned with the SOGC recommendation that women be given the opportunity to consult with her obstetric care provider on the risks and benefits of TOLAC as well as awareness of availability of hospital resources for an elective cesarean section if indicated [12]. Adoption of any strategy or intervention to increase rates of TOLAC and subsequent VBAC must carefully weigh the potential benefits against the possible risks for mother and baby. 
As the scope of the current review was sufficiently broad, the authors did not search for studies that examined barriers to VBAC or factors related to women's motivations, preferences or decision-making. Studies of clinicians' and women's perspectives may provide insight on system, provider-level, and patient-oriented factors that influence rates of attempted and successful VBAC $[48,49]$. For example, a qualitative study examined barriers associated with the ACOG VBAC guidelines and found that fear of liability affected the willingness of midwives and obstetricians in offering VBAC [6]. Other factors such as the continual presence of a physician, travel distance to a hospital that offers TOLAC (although $56 \%$ of California hospitals permit TOLAC, significantly fewer VBACs were actually carried out), and hospital policy for patient TOLAC eligibility presented as other systemic barriers restricting women's access to a TOLAC [50]. Additionally, there is a paucity of studies on supports intended to facilitate shared decision-making between women and their healthcare providers [51]. Such evidence may provide context for effectiveness, acceptability and feasibility of interventions aimed at individual patients' needs, decisions and satisfaction regarding mode of birth.

\section{Conclusion}

This 'up-to-date' systematic review evaluated adjunct clinical interventions directed at increasing the rate of vaginal delivery among women with a prior cesarean delivery and provides evidence that some provider-level interventions and provider characteristics are associated with higher maternal TOLAC and VBAC rates. Further research, using robust study designs with documentation of population characteristics, is needed to provide stronger outcome evidence for the use and effect of adjunct clinical interventions. Enhancing the woman's education and her opportunity to consider and choose VBAC over a repeat cesarean delivery is an important clinical outcome and goal to examine in future research and reviews.

\section{Additional file}

Additional file 1: Appendix 1. Search strategy. Appendix 2. Characteristics of included studies. Appendix 3. Methodological quality assessments of included studies. (PDF $424 \mathrm{~kb}$ )

\footnotetext{
Abbreviations

ACOG: American College of Obstetrics and Gynecology; aOR: adjusted odds ratio; BMI: Body mass index; Cl: Confidence interval; GA: Gestational age; GRADE: Grading of Recommendations Assessment, Development and Evaluation; MMAT: Mixed Methods Appraisal Tool; NRCT: Non-randomized clinical trial; OR: Odds ratio; RCT: Randomized clinical trial; RR: Risk ratio; SMFM: The Society for Maternal-Fetal Medicine; SOGC: The Society of Obstetricians and Gynaecologists of Canada; TOLAC: Trial of labor after cesarean; VBAC: Vaginal birth after cesarean
}

\section{Acknowledgements}

We would like to thank: Tara Landry, MLIS, for peer reviewing the search strategy; Ms. MacKinna Hauff for article retrieval; Dr. Allison Gates and Dr. Michelle Gates for assistance with the French translations.

\section{Funding}

This study was funded by the Maternal, Newborn, Child and Youth Strategic Clinical Network (MNCY SCN) of Alberta Health Services (AHS) and the Alberta Strategy for Patient-Oriented Research (SPOR) SUPPORT Unit Knowledge Translation Platform. The funders had no role in the design of the study, the collection, analysis or interpretation of data, the writing of the manuscript, or the decision to submit the article for publication.

\section{Availability of data and materials}

All data generated or analyzed during this study are included in this published article (and its supplementary information files).

\section{Authors' contributions}

All authors contributed to the conception and design of the project. RF conducted the literature searches. AW and CJ conducted screening, quality assessments, and data extraction and verification. AW drafted the manuscript. AW, CJ, MS, LH and RDW contributed to interpretation of data and revised the manuscript for important intellectual content. All authors contributed to revisions of the manuscript and approved the final version for submission.

\section{Ethics approval and consent to participate}

This is a systematic review of previously published data and as such does not require ethics approval.

\section{Consent for publication}

Not applicable.

\section{Competing interests}

All authors declare funding from MNCY SCN of AHS and Alberta SPOR SUPPORT Unit KT Platform; LH, MS and RF are employed in part or whole by the Alberta SPOR SUPPORT KT Platform; LH was funded in part by a New Investigator Salary Award from CIHR; there are no other relationships or activities that could appear to have influenced the submitted work.

\section{Publisher's Note}

Springer Nature remains neutral with regard to jurisdictional claims in published maps and institutional affiliations.

\section{Author details \\ ${ }^{1}$ Alberta Research Centre for Health Evidence, Department of Pediatrics, University of Alberta, Edmonton, AB, Canada. ${ }^{2}$ Alberta Strategy for Patient-Oriented Research (SPOR) SUPPORT Unit Knowledge Translation Platform, University of Alberta, Edmonton, AB, Canada. ${ }^{3}$ Department of Obstetrics and Gynecology, Cumming School of Medicine, University of Calgary, 1403 - 29 Street NW, Calgary, AB T2N 2T9, Canada.}

Received: 1 June 2018 Accepted: 18 October 2018

Published online: 21 November 2018

References

1. Canadian Institute of Health Information. Inpatient hospitalizations, surgeries and childbirth indicators in 2010-2013. https://secure.cihi.ca/estore/ productFamily.htm. Accessed 5 May 2017.

2. Kelly S, Sprague A, Fell DB, Murphy P, Aelicks N, Guo Y, et al. Examining caesarean section rates in Canada using the Robson classification system. J Obstet Gynaecol Can. 2013;35(3):206-14.

3. Canadian Institute for Health Information. Health indicators 2014: caesarean section. 2014. https://yourhealthsystem.cihi.ca/. Accessed 5 May 2017.

4. World Health Organization. WHO statement on caesarean section rates. 2015. http://www.who.int/reproductivehealth/publications/maternal_ perinatal_health/cs-statement/en/. Accessed 5 May 2017.

5. Brown HK, Hill J, Natale R. Caesarean section rates in southwestern Ontario: changes over time after adjusting for important medical and social characteristics. J Obstet Gynaecol Can. 2014;36(7):578-89. 
6. Cox KJ. Providers' perspectives on the vaginal birth after cesarean guidelines in Florida, United States: a qualitative study. BMC Pregnancy Childbirth. 2011;11(1):72

7. Johnson J-A, Tough S, SOGC Genetics Committee. Delayed child-bearing. J Obstet Gynaecol Can. 2017;34(1):80-93.

8. Joseph KS, Young DC, Dodds L, O'Connell CM, Allen VM, Chandra S, et al. Changes in maternal characteristics and obstetric practice and recent increases in primary cesarean delivery. Obstet Gynecol. 2003;102(4):791-800.

9. Kawakita T, Reddy UM, Landy HJ, lqbal SN, Huang CC, Grantz KL. Indications for primary cesarean delivery relative to body mass index. Am J Obstet Gynecol. 2016;215(4):e1-9.

10. Born K, Konkin J, Tepper J, Okan N. Pulling back the curtain on Canada's rising c-section rate. 2014. http://healthydebate.ca/2014/05/topic/quality/csection-variation. Accessed 5 May 2017.

11. Degani N, Sikich N. Caesarean delivery rate review: an evidence-based analysis. Ont Health Technol Assess Ser. 2015;15(9):1-58.

12. Martel MJ, MacKinnon CJ. Clinical practice obstetrics committee. Guidelines for vaginal birth after previous caesarean. J Obstet Gynaecol. 2018;40(3): e195-207.

13. Sabol B, Denman MA, Fuise JM. Vaginal birth after cesarean: an effective method to reduce cesarean. Clin Obstet Gynecol. 2015;58(2):309-19.

14. Grobman WA, et al. The change in the rate of vaginal birth after caesarean section. Paediatr Perinat Epidemiol. 2011;25(1):37-43.

15. American Congress of Obstetricians and Gynecologists. ACOG practice bulletin: vaginal birth after cesarean delivery. Practice bulletin; 2017. p. 130

16. American Congress of Obstetricians and Gynecologists. New VBAC guidelines. What they mean to you and your patients. ACOG Today. 2010; 54(4):6-7.

17. American Congress of Obstetricians and Gynecologists. ACOG practice bulletin no. 115: vaginal birth after previous cesarean delivery. Obstet Gynecol. 2010;116:450-463.

18. Higgins J, Green S (editors). The Cochrane Handbook for Systematic Reviews of Interventions 5.1.0 [updated: March 2011]. The Cochrane Collaboration; 2011. www.cochrane-handbook.org. Accessed: 14 Nov 2017.

19. Moher D, Liberati A, Tetzlaff J, Altman DG. Preferred reporting items for systematic reviews and meta-analyses: the PRISMA statement. J Clin Epidemiol. 2009;62(10):1006-12.

20. Pace R, Pluye P, Bartlett G, Macaulay AC, Salsberg J, Jagosh J, et al. Testing the reliability and efficiency of the pilot mixed methods appraisal tool (MMAT) for systematic mixed studies review. Int J Nurs Stud. 2012;49(1):47-53.

21. Guyatt GH, Oxman AD, Schunemann HJ, Tugwell P, Knottnerus A. GRADE guidelines: a new series of articles in the journal of clinical epidemiology. $J$ Clin Epidemiol. 2011;64(4):380-2.

22. Ayres-De-Campos D, Cruz J, Medeiros-Borges C, Costa-Santos C, Vicente L. Lowered national cesarean section rates after a concerted action. Acta Obstet Gynecol Scand. 2015;94(4):391-8.

23. Bellows P, Shah U, Hawley L, Drexler K, Gandhi M, Sangi-Haghpeykar H, et al. Evaluation of outcomes associated with trial of labor after cesarean delivery after a change in clinical practice guidelines in an academic hospital. J Matern Fetal Neonatal Med. 2016:1-5

24. Bickell NA, Zdeb MS, Applegate MS, Roohan PJ, Sui AL. Effect of external peer review on cesarean delivery rates: a statewide program. Obstet Gynecol. 1996;87(5 Pt 1):664-7.

25. Cleary-Goldman J, Cornelisse K, Simpson LL, Robinson JN. Previous cesarean delivery: understanding and satisfaction with mode of delivery in a subsequent pregnancy in patients participating in a formal vaginal birth after cesarean counseling program. Am J Perinatol. 2005;22(4):217-21.

26. Eden KB, Perrin NA, Vesco KK, Guise JM. A randomized comparative trial of two decision tools for pregnant women with prior cesareans. J Obstet Gynecol Neonatal Nurs. 2014:43(5):568-79.

27. Feldman DS, Bollman DL, Fridman M, Korst LM, El Haj IS, Fink A, et al. Do laborists improve delivery outcomes for laboring women in California community hospitals? Am J Obstet Gynecol. 2015;213(4):587 e1-13.

28. Fraser W, Maunsell E, Hodnett E, Moutquin JM. Randomized controlled tria of a prenatal vaginal birth after cesarean section education and support program. Childbirth alternatives post-cesarean study group. Am J Obstet Gynecol. 1997;176(2):419-25.

29. Gardner K, Henry A, Thou S, Davis G, Miller T. Improving VBAC rates: the combined impact of two management strategies. Aust N Z J Obstet Gynaecol. 2014;54(4):327-32.
30. Kosecoff J, Kanouse DE, Rogers WH, McCloskey L, Winslow CM, Brooks RH. Effects of the National Institutes of Health consensus development program on physician practice. JAMA. 1987;258(19):2708-13.

31. Liu CM, Lin YJ, Su YY, Chang SD, Cheng PJ. Impact of health policy based on the self-management program on cesarean section rate at a tertiary hospital in Taiwan. J Formos Med Assoc. 2013;112(2):93-8.

32. Lomas J, Enkin M, Anderson GM, Hannah WJ, Vayda E, Singer J. Opinion leaders vs audit and feedback to implement practice guidelines. Delivery after previous cesarean section. JAMA. 1991;265(17):2202-7.

33. Montgomery AA, Emmett CL, Fahey T, Jones C, Ricketts I, Patel RR, et al. the DiAMOND Study Group. Two decision aids for mode of delivery among women with previous caesarean section: randomised controlled trial. BMJ. 2007:334(7607):1305.

34. Myers SA, Gleicher N. The Mount Sinai cesarean section reduction program: an update after 6 years. Soc Sci Med. 1993;37(10):1219-22.

35. Pinette MG, Kahn J, Gross KL, Wax JR, Blackstone J, Cartin A. Vaginal birth after cesarean rates are declining rapidly in the rural state of Maine. J Matern Fetal Neonatal Med. 2004;16(1):37-43.

36. Russillo B, Sewitch MJ, Cardinal L, Brassard N. Comparing rates of trial of labour attempts, VBAC success, and fetal and maternal complications among family physicians and obstetricians. J Obstet Gynaecol Can. 2008; 30(2):123-8.

37. Sanchez-Ramos L, Kaunitz AM, Peterson HB, Martinez-Schnell B, Thompson RJ. Reducing cesarean sections at a teaching hospital. Am J Obstet Gynecol. 1990;163(3):1081-7.

38. Santerre RE. The effect of the ACOG guideline on vaginal births after cesarean. Med Care Res Rev. 1996;53(3):315-29.

39. Studnicki J, Remmel R, Campbell R, Werner DC. The impact of legislatively imposed practice guidelines on cesarean section rates: the Florida experience. Am J Med Qual. 1997;12(1):62-8.

40. White H, Le May A, Cluett E. Evaluating a midwife-led model of antenatal care for women with a previous caesarean section: a retrospective, comparative cohort study. Br J Obstet Gynaecol. 2016:123:200-8.

41. Wong KW, Thomas JM, Andrews V. Are women's and obstetricians, views on mode of delivery following a previous cesarean section really OCEANS apart? J Obstet Gynaecol India. 2014;64(6):400-2

42. Yee LM, Liu LY, Grobman WA. Obstetrician call schedule and obstetric outcomes among women eligible for a trial of labor after cesarean. Am J Obstet Gynecol. 2017;216(1):75 e1-6.

43. Zhang T, Liu C. Comparison between continuing midwifery care and standard maternity care in vaginal birth after cesarean. Pak J Med Sci. 2016; 32(3):711-4.

44. Zweifler J, Garza A, Hughes S, Stanich MA, Hierholzer A, Lau M. Vaginal birth after cesarean in California: before and after a change in guidelines. Ann Fam Med. 2006;4(3):228-34.

45. Catling-Paull C, Johnston R, Ryan C, Foureur MJ, Homer CS. Non-clinical interventions that increase the uptake and success of vaginal birth after caesarean section: a systematic review. J Adv Nurs. 2011;67(8):1662-76.

46. Lundgren I, Smith V, Nilsson C, Vehvilainen-Julkunen K, Nicoletti J, Devane $D$, et al. Clinician-centred interventions to increase vaginal birth after caesarean section (VBAC): a systematic review. BMC Pregnancy Childbirth. 2015;15(16):1-9.

47. Nilsson C, Lundgren I, Smith V, Vehnilainen-Julkunen K, Nicoletti J, Devane $D$, et al. Women-centred interventions to increase vaginal birth after caesarean section (VBAC): a systematic review. Midwifery. 2015;31(7):657-63.

48. Lundgren I, van Limbeek E, Vehvilainen-Julkunen K, Nilsson C. Clinicians' views of factors of importance for improving the rate of VBAC (vaginal birth after caesarean section): a qualitative study from countries with high VBAC rates. BMC Pregnancy Childbirth. 2015:15(196):1-12.

49. Nilsson C, van Limbeek E, Vehvilainen-Julkunen K, Lundgren I. Vaginal birth after cesarean: views of women from countries with high VBAC rates. Qual Health Res. 2017;27(3):325-40.

50. Barger MK, Dunn JT, Bearman S, DeLain M, Gates E. A survey of access to trial of labor in California hospitals in 2012. BMC Pregnancy Childbirth. 2013;13:83.

51. Horey D, Kealy M, Davey MA, Small R, Crowther CA. Interventions for supporting pregnant women's decision-making about mode of birth after a caesarean. Cochrane Database Syst Rev. 2013;7:CD010041. 